\title{
Is Drainage of Abdominal Cavity Necessary After Laparoscopic Appendectomy?
}

\author{
Jurij Janež* \\ Department of Abdominal Surgery, University Medical Centre Ljubljana, Slovenia
}

Received: June 2, 2018; Published: July 02, 2018

*Corresponding author: Jurij Janež, Department of Abdominal Surgery, University Medical Centre Ljubljana, Zaloška cesta 7, 1525 Ljubljana, Slovenia, Europe

\section{Introduction}

Acute appendicitis is one of the most common causes of acute abdominal pain and is one of the most common surgical abdominal emergencies. Nowadays, patients with acute appendicitis are managed in most cases with laparoscopic appendectomy, which is usually performed through three small skin incisions and three trocars [1]. In the past, conventional open appendectomy was the treatment of choice and was the gold standard of treatment for patients with acute appendicitis. In open appendectomy, a small skin incision in the right inferior abdominal quadrant over BcBurney point was performed and the appendix was removed through a relatively small wound. An abdominal drain was rarely used after open appendectomy. Certain studies suggested increased intra-abdominal abscess rates following laparoscopic appendectomy, especially for perforated appendicitis, because of this drainage of the abdominal cavity is more common after laparoscopic appendectomy [2]. The routine use of abdominal drain after laparoscopic appendectomy is still under debate.

The placement of the abdominal drain could be useful in cases of perforated appendicitis with peritonitis, since some studies have shown more intra-abdominal abscesses formation after perforated appendicitis. None of the prospective randomized clinical trials have shown the benefits of routine drainage of the abdominal cavity after laparoscopic appendectomy for uncomplicated acute appendicitis. Even in complicated acute appendicitis, the placement of intra-abdominal drain may not present benefits and may even lengthen hospital stay. The Jerusalem guidelines from the year 2016, that were proposed by the World Society of Emergency Surgeons, suggest selective and cautious use of abdominal drainage after laparoscopic appendectomy, because there is no good evidence in the literature [1]. Some authors suggest that there is no need of using a drain in laparoscopic appendectomy for complicated acute appendicitis [3]. However, according to some other authors, the use of intra-abdominal drainage in patients with perforated or gangrenous appendicitis during laparoscopic appendectomy has decreased rates of pelvic abscess [4].
Routine prophylactic abdominal drains after laparoscopic appendectomy for perforated appendicitis in children are still controversial. Throughout the history of surgery, potential benefits of the abdominal drains have been described. However, in recent studies, no benefits were observed, and serious complications have been reported. The prophylactic use of abdominal drainage after laparoscopic appendectomy for perforated appendicitis in children does not prevent postoperative complications and may be associated with negative outcomes. Further prospective randomized studies will be necessary to verify this question [5]. Drainage of the abdominal cavity after laparoscopic appendectomy should be selective and cautious, because in the literature no good evidence exists of their benefits. Abdominal drains are not necessary after laparoscopic appendectomy for uncomplicated acute appendicitis. In cases of perforated acute appendicitis, the use of abdominal drains should be selective according to intraoperative findings, degree of peritonitis or presence of intra-abdominal abscesses.

\section{References}

1. Salomone Di Saverio, Arianna Birindelli, Micheal D Kelly, Fausto Catena, Dieter G Weber, et al. (2016) WSES Jerusalem guidelines for diagnosis and treatment of acute appendicitis. World Journal of Emergency Surgery 11: 34

2. Katkhouda N, Friedlander MH, Grant SW, Achanta KK, Essani R, et al.(2000) Intraabdominal abscess rate after laparoscopic appendectomy. Am J Surg 180(6): 456-459.

3. Pakula AM, Skinner R, Jones A, Chung R, Martin M (2014) Role of drains in laparoscopic appendectomy for complicated appendicitis at a busy county hospital. Am Surg 80(10): 1078-1081.

4. Schlottmann F, Reino R, Sadava EE, Campos ArbulúA, Rotholtz NA(2016) Could an abdominal drainage be avoided in complicated acute appendicitis lessons learned after 1300 laparoscopic appendectomies. Int J Surg 36: 40-43.

5. Aneiros Castro B, Cano I, García A, Yuste P, Ferrero E, et al. (2018) Abdominal drainage after laparoscopic appendectomy in children: an endless controversy. Scand J Surg 1: 1457496918766696. 
(c) This work is licensed under Creative Submission Link: https://biomedres.us/submit-manuscript.php

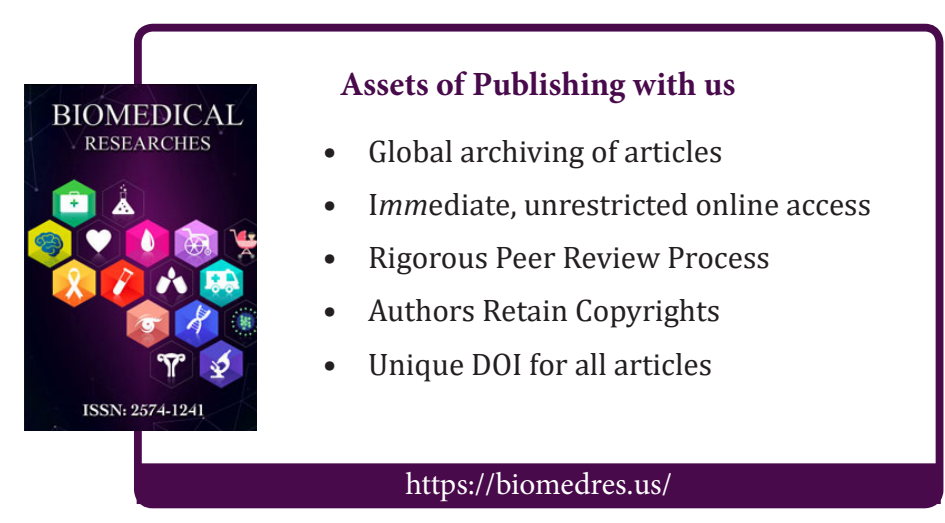

